\title{
Inorganic Polymer Engineering Materials
}

\author{
M. L. Stone
}

Published June 1993

Idaho National Engineering Laboratory

EG\&G Idaho, Inc.

Idaho Falls, Idaho 83415

Prepared for the

U.S. Department of the Interior, Bureau of Mines

Under Contract J1034035

and for the

U.S. Department of Energy

Under DOE Idaho Operations Office

Contract DE-AC07-76ID01570 


\begin{abstract}
Phosphazene-based, inorganic-polymer composites have been produced and evaluated as potential engineering materials. The thermal, chemical, and mechanical properties of several different composites made from one polymer formulation have been measured. The measured properties are very good, and the composites show excellent promise for structural applications in harsh environments.

Chopped fiberglass, mineral, cellulose, and woodflour filled composites were tested. Chopped fiberglass filled composites showed the best overall properties. The phosphazene composites are very hard and rigid. They have low dielectric constants and typical linear thermal expansion coefficients for polymers. In most cases, the phosphazene materials performed as well or better than analogous, commercially available, filled phenolic composites. After 3 to 5 weeks of exposure, both the phosphazene and phenolics were degraded in aqueous bases and acids. The glass filled phosphazene samples were least affected.
\end{abstract}




\section{ACKNOWLEDGMENTS}

Ine author acknowledges the contributions of Dr. Douglas Femec for modifying and developing the prepolymer synthesis, of Dr. Michael O'Brien for performing mechanical testing and interpreting the data, of Dr. Melvin Herd for developing the statistical set of experiments for optimizing test bar fabrication, and of Johanna Salsman of the USBM Tuscaloosa Research Center for determining dielectric constants. 


\section{CONTENTS}



ACKNOWLEDGMENTS $\ldots \ldots \ldots \ldots \ldots \ldots \ldots \ldots \ldots \ldots \ldots \ldots \ldots \ldots \ldots \ldots$

INTRODUCTION $\ldots \ldots \ldots \ldots \ldots \ldots \ldots \ldots \ldots \ldots \ldots \ldots \ldots \ldots \ldots \ldots \ldots \ldots \ldots$

BACKGROUND $\ldots \ldots \ldots \ldots \ldots \ldots \ldots \ldots \ldots \ldots \ldots \ldots \ldots \ldots \ldots \ldots \ldots \ldots \ldots \ldots \ldots \ldots$

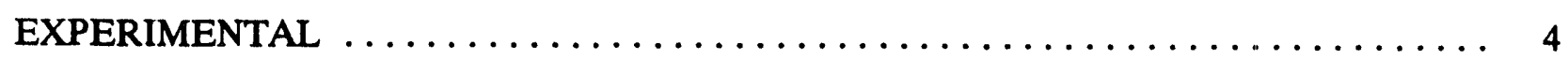

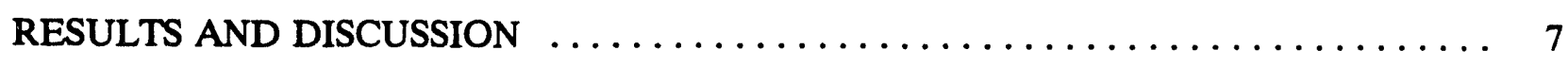

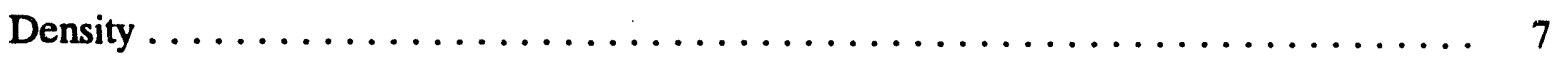

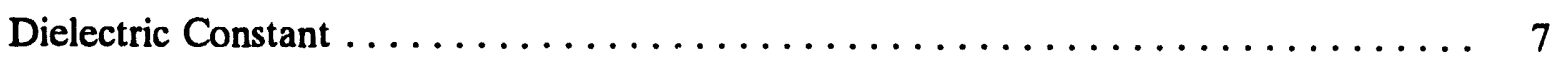

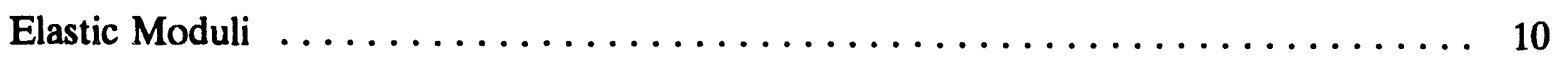

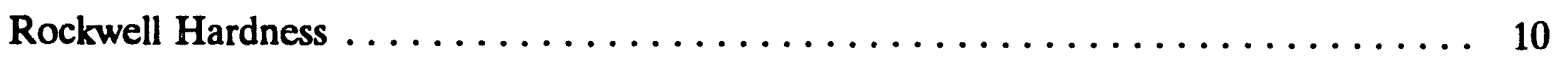

Statistical Set of Experiments for Optimizing Test Bar Fabrication $\ldots \ldots \ldots \ldots \ldots 11$

Coefficients of Linear Thermal Expansion $\ldots \ldots \ldots \ldots \ldots \ldots \ldots \ldots \ldots \ldots \ldots \ldots$

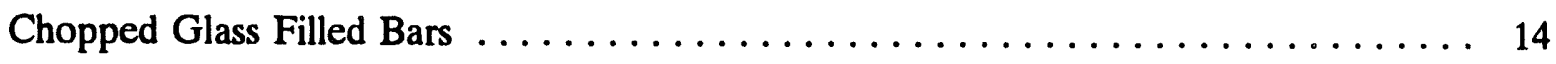

Flexural Strengths and Relative Modulus $\ldots \ldots \ldots \ldots \ldots \ldots \ldots \ldots \ldots \ldots \ldots$

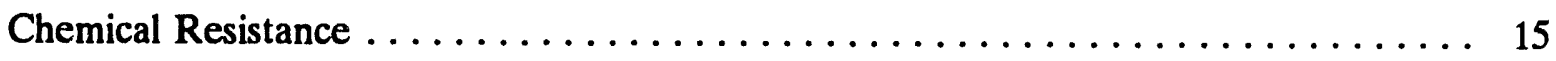

Organic Liquids (Ethanol, Toluene, Acetone, and

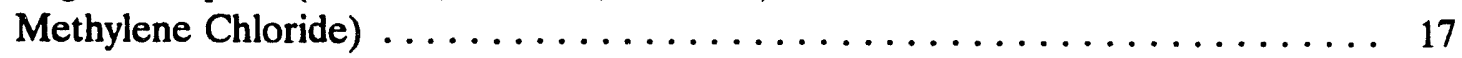

Aqueous Acid and Base $\left(1 \mathrm{M} \mathrm{H}_{2} \mathrm{SO}_{4}\right.$ and $\left.1 \mathrm{M} \mathrm{NaOH}\right) \ldots \ldots \ldots \ldots \ldots \ldots$

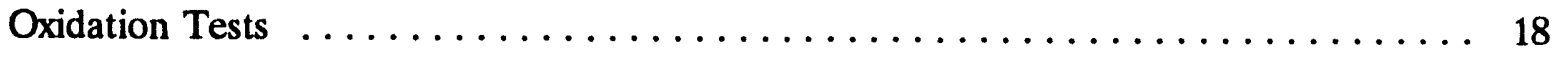

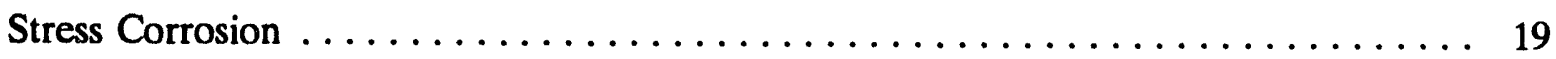

Elevated Temperature Flexural Strengths $\ldots \ldots \ldots \ldots \ldots \ldots \ldots \ldots \ldots \ldots .21$

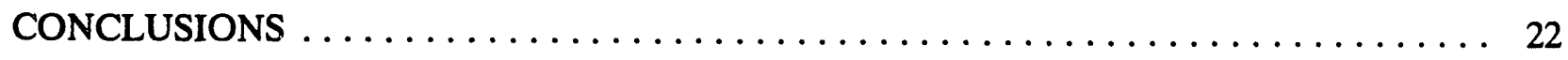

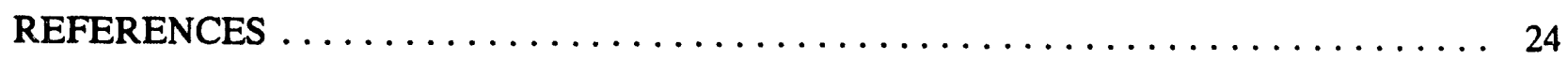




\section{FIGURES}

1. Polyphosphazene backbone configurations $\ldots \ldots \ldots \ldots \ldots \ldots \ldots \ldots \ldots \ldots$



3. Dielectric constants of the unfilled cyclomatrix material.

Temperatures: $25^{\circ} \mathrm{C}=\square-\square ; 50^{\circ} \mathrm{C}=+-+; 100^{\circ} \mathrm{C}=*-*$;

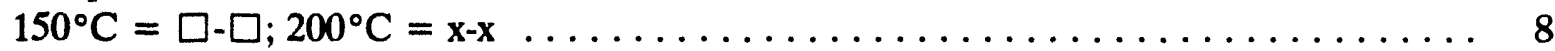

4. Dielectric constants of the six filled materials (as indicated).

Temperatures: $25^{\circ} \mathrm{C}=\mathbf{n} ; 50^{\circ} \mathrm{C}=+-+; 100^{\circ} \mathrm{C}=*-*$;

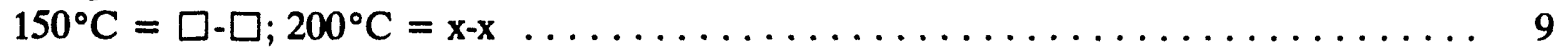

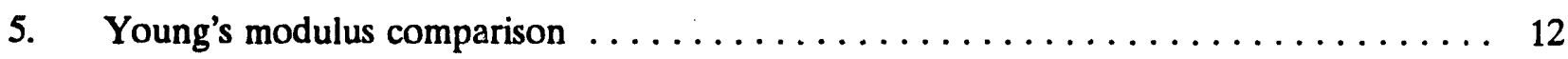

6. Rockwell hardness comparison $\ldots \ldots \ldots \ldots \ldots \ldots \ldots \ldots \ldots \ldots \ldots \ldots \ldots \ldots$

7. Flexural strengths of cyclomatrix and phenolic bars $\ldots \ldots \ldots \ldots \ldots \ldots \ldots \ldots$

8. Relative modulus of cyclomatrix and phenolic bars $\ldots \ldots \ldots \ldots \ldots \ldots \ldots$

9. Flexural strengths after immersion in organic solvents

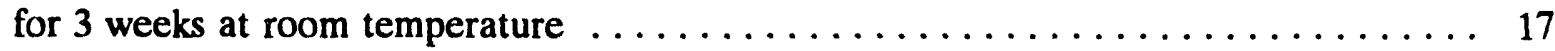

10. Flexural strengths after immersion in acid and base

for 3 weeks at room temperature $\ldots \ldots \ldots \ldots \ldots \ldots \ldots \ldots \ldots \ldots \ldots \ldots \ldots$

11. Flexural strengths of chopped glass filled polyphosphazene

composites after 3 weeks of immersion in the indicated chemicals

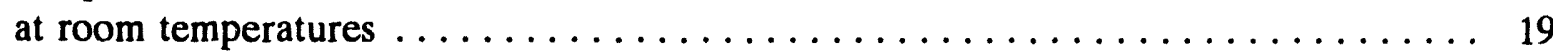

12. Elevated temperature flex strengths $\ldots \ldots \ldots \ldots \ldots \ldots \ldots \ldots \ldots \ldots \ldots \ldots \ldots$

TABLES

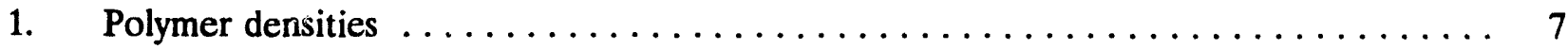

2. The dielectric constants for selected polymers at $1 \mathrm{MHz} \ldots \ldots \ldots \ldots \ldots \ldots \ldots$

3. Cyclomatrix moduli measured by ultrasonic velocities $\ldots \ldots \ldots \ldots \ldots \ldots \ldots \ldots$

4. B-coefficient ranking of the design variables $\ldots \ldots \ldots \ldots \ldots \ldots \ldots \ldots \ldots \ldots$

5. Coefficients of linear thermal expansion $\ldots \ldots \ldots \ldots \ldots \ldots \ldots \ldots \ldots \ldots$ 
6. Total weight loss (wt\%) after heat soaks of 1 hour and 2 hours

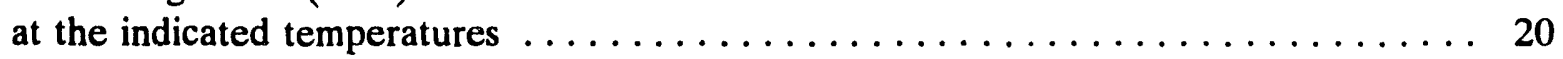

7. Weight loss after 8 weeks of exposure at $200^{\circ} \mathrm{C}$ in air $\ldots \ldots \ldots \ldots \ldots \ldots$ 


\section{Inorganic Polymer Engineering Materials}

\section{INTRODUCTION}

The objective of this project was to investigate and evaluate the use of phosphazene polymers as engineering materials to form strong, temperature and chemically resistant composite structures. The properties were compared with commercially available phenol-formaldehyde composites, because the same crosslinking system was present in both types of composites.

Composites include polymeric binders containing fillers. There are hundreds of combinations of fillers and resins commercially available today. Most of the polymers are organic-based materials, that is, they have carbon, hydrogen, and oxygen as the major constituents in their backbones. Many of these polymers have excellent properties, but materials with higher thermal and chemical resistance are always needed. This program was a scoping study designed to review properties of an inorganic-backboned polymer in an attempt to produce materials with improved properties. The material selected for this investigation is called polyphosphazene and is characterized by having a backbone of alternating phosphorus and nitrogen atoms.

The program began by selecting one representative polymer. Unfilled bars were molded to develop the necessary processing parameters. This program included a statistically designed set of experiments to aid in developing a fabrication recipe that would consistently produce quality bars. The unfilled materials were characterized as to their densities, dielectric constants, various mechanical moduli, and chemical resistance. Three filled composite types were then made (cellulose, wood flour, and mineral) and compared with commercially available phenolic materials. Finally, bars containing chopped fiberglass were produced and evaluated. 


\section{BACKGROUND}

Wide industrial and consumer applications for organic polymers have been found in recent years due to advances in polymer chemistry. Some of these polymers, however, cannot operate in harsh environments due to their organic chemical backbones. To overcome these limitations, an investigation into the use of inorganic polymers as engineering materials was undertaken. The class of inorganic polymers studied in this program is known as polyphosphazenes. These materials were selected because they have an inorganic backbone and because this family of polymers is large, which allows the user to tailor a material for a specific application.

The phosphazene unit consists of alternating nitrogen and phosphorus atoms. Each phosphorus atom is doubly bonded to one nitrogen in the backbone and singly bonded to another. Two side groups ("R" groups; these are chemical side groups that differentiate one polymer from another) are also attached to each phosphorus. The three types of backbones that the phosphazenes can have are illustrated in Figure 1. The first is called linear because of the apparent linearity of the phosphorus-to-nitrogen bonding pattern. The next is called cyclolinear because the cyclic phosphazene units are attached in a linear-like fashion. The third configuration is called cyclomatrix due to the highly crosslinked nature of the cyclic phosphazene units.

The combination of the three backbones with the multiplicity of available " $R$ " groups yields an enormous variety of combinations from which to choose. The linear polymers are generally rubbery, stretchy, and flexible. Whereas, the cyclomatrix materials, with all of the additional crosslinking possible, are much more rigid and hard and therefore were selected as the materials for this study. 


\section{Linear Backbone}

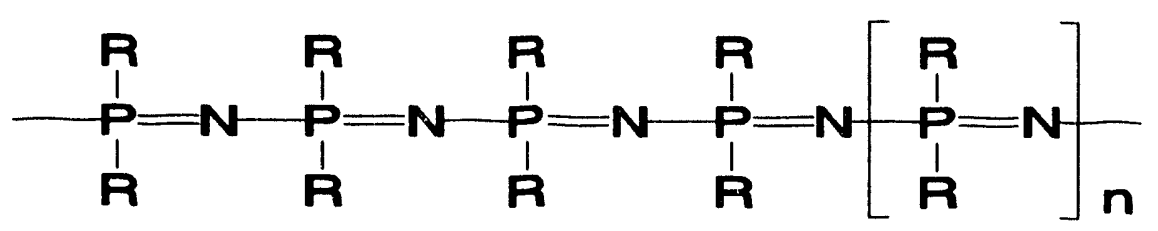

\section{Cyclolinear Backbone}<smiles>[R]P1([R])=NP([R])([R])=NP([R])(P2(P)=NP([R])(P)=NP([R])([R])=N2)=N1</smiles>

\section{Cyclomatrix Backbone}

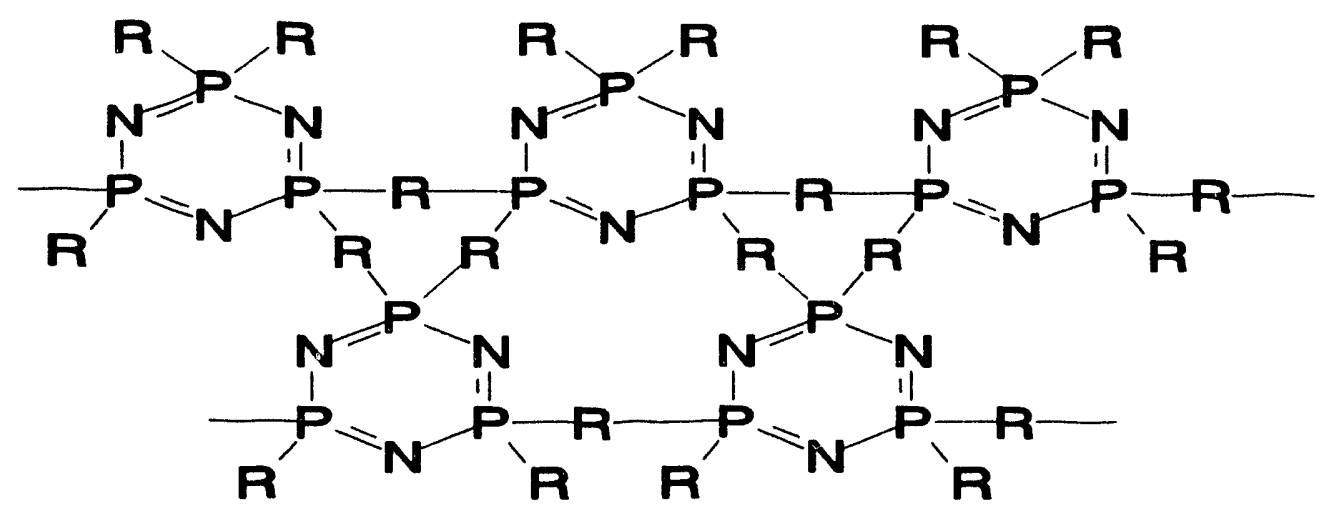

Figure 1. Polyphosphazene backbone configurations. 


\section{EXPERIMENTAL}

The cyclomatrix prepolymer selected for study was hexa-p-hydroxyphenoxycyclotriphosphazene. It was synthesized from the combination of the chlorinated phosphazene cyclic trimer with hydroquinone in cyclohexane in the presence of a base according to the scheme shown in Figure 2.

All of the testing was performed in-house except for the dielectric constants and the linear expansion coefficients. The Archimedes method was used to determine the densities. Hardness was measured according to American Society for Testing and Materials (ASTM) D 785 "Rockwell Indentation Hardness Test" specifications for the Rockwell M category of materials. ASTM E949 "Measuring Ultrasonic Velocity in Materials" method was used to measure shear modulus, Youn?'s modulus, Poisson's ratio, and the bulk modulus. Flexural strengths were measured according to ASTM D 790 "Flexural Properties of Unreinforced and Reinforced Plastics and Electrical Insulating Materials." All reported flexural strengths are the average of triplicate samples.

There are not any ASTM or Society of Automotive Engineers (SAE) stress corrosion tests available for hard, rigid, plastic materials. An SAE test for a flexible material was modified to give a workable stress corrosion test [SAE J2016 (June 1989, "Chemical Stress Resistance of Polymers")]. Bars were flexed 10 to $20 \%$ of their breaking values and then the tensile-stressed surface was continually kept moistened with six liquids, each for a total of 30 minutes. At 10-minute intervals, the surface was examined for stress cracking.

The oxidation resistance was measured by heating samples in air and noting weight and appearance changes after exposure for 1 and 2 hours. This was done at 300,250 , and $200^{\circ} \mathrm{C}$. At $200^{\circ} \mathrm{C}$, none of the bars lost more than $5 \%$ of their weight, so an 8-week oxidation test was run at $200^{\circ} \mathrm{C}$, again monitoring weight and appearance changes.

The statistical set of experiments developed for preparation of test speciments was based upon a commercially available computer-based design strategy by Edgework Inc., Seattle, WA.

Three filled phenolic compounds and three fillers were purchased from the Valite Division of Valentine Sugars, Inc., Lockport, LA. The phenolic was a phenol formaldehyde polymeric molding compound. The three fillers were mineral (aluminum silicate, $\mathrm{Al}_{2} \mathrm{O}_{3} \cdot 2 \mathrm{SiO}_{2} \cdot 2 \mathrm{H}_{2} \mathrm{O}$ ), woodflour (hard and soft wood), and cellulose (cotton flock, grade \#D 200). The loading level of the filler in the phenolics was not known. The phenolic test bars were molded at $177^{\circ} \mathrm{C}$ for 15 minutes at $2,000 \mathrm{psi}$, then the bars were heat soaked for 2 hours at $100^{\circ} \mathrm{C}$.

Chopped fiberglass was supplied by Idaho Chemical Industries, Boise, ID. It was 1/16 in. long, unsized glass from Owens-Corning Fiberglas Corporation, Toledo, $\mathrm{OH}$.

The USBM Tuscaloosa Research Center determined the dielectric constants for seven types of bars in the 0.3 to $3 \mathrm{GHz}$ frequency range at temperatures between 25 and $200^{\circ} \mathrm{C}$. These bars were cyclomatrix polyphosphazene bars with either no filler or $60 \mathrm{wt} \%$ of each of the three fillers and the commercial phenolic bars containing the same three fillers. 

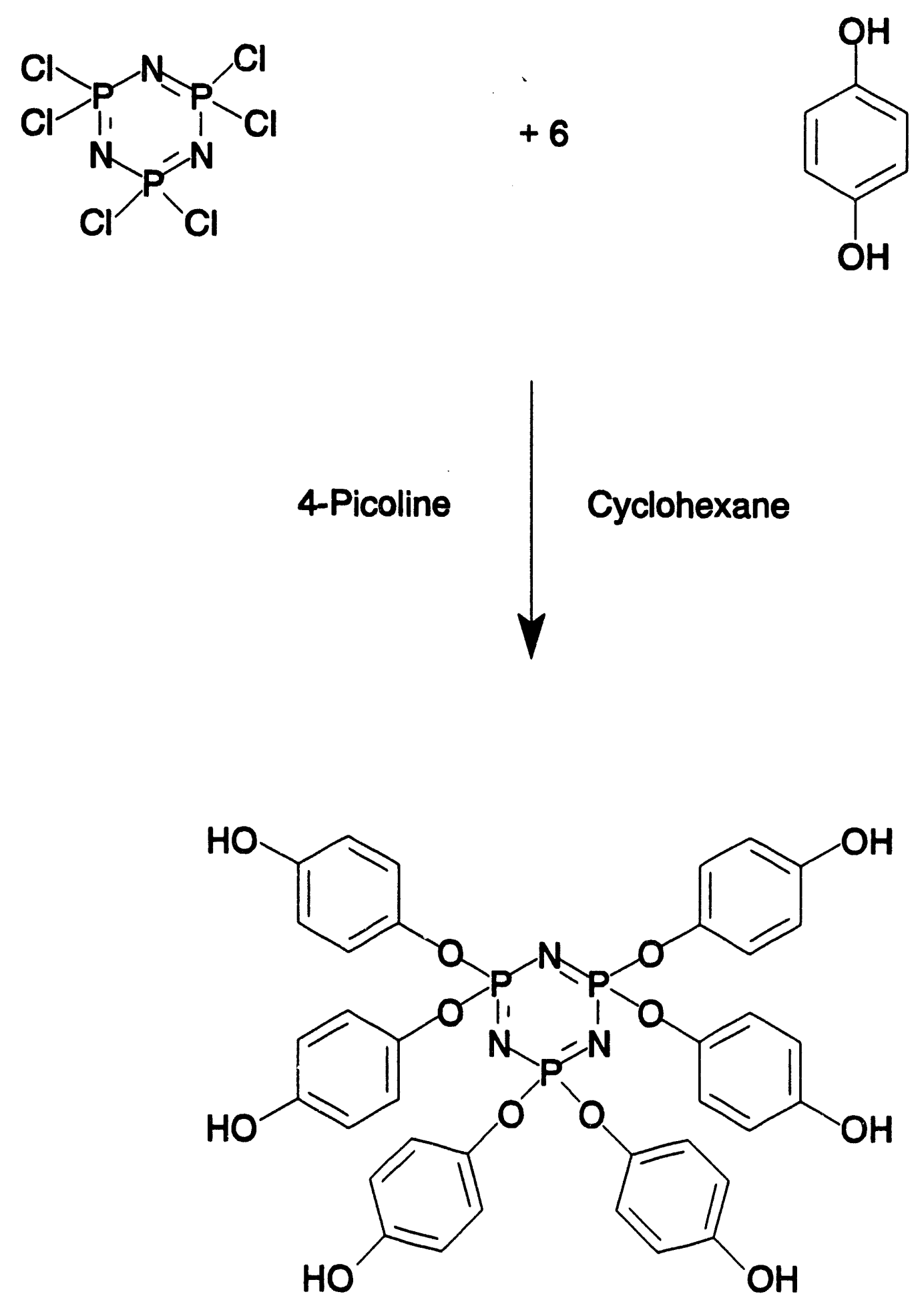

Figure 2. Prepolymer synthesis. 
Delsen Testing Laboratories, Glendale, CA, performed the coefficient of linear thermal expansion measurements. ASTM E 831-86 was used as a guide. The samples were tested "as received." The heating rate was $10^{\circ} \mathrm{C} /$ minute in air up to $300^{\circ} \mathrm{C}$. The specimens were removed from the middle of the bars, and the expansion of the long axis (the length) of the bars was determined. The specimen was heated from ambient to $300^{\circ} \mathrm{C}$. Only the linear region of the curve was used to evaluate the expansion coefficients.

Equipment and instruments used to produce and test the samples in this program were calibrated according the direction and frequency of the standards and calibration group within EG\&G Idaho.

The chemical resistance of the materials was measured by .wo methods. One was to measure the flexural strengths after chemical exposure at room temperature for 3 weeks. The other method was to monitor the weight/appearance changes in the bars after chemical exposure at room temperature for 1 year. In both of these experiments, six separate sets containing each type of material were used. Each of the sets of base was immersed in one test liquid. One set was immersed in the acid, another in the base, and so on for each of the four organic solvents. 


\section{RESULTS AND DISCUSSION}

\section{Density}

The average densities of four unfilled cyclomatrix bars are listed in Table 1. For comparison, the densities of several commercial resins taken from the literature (including the filled phenolics ${ }^{1}$ ) are also listed in the table.

Table 1. Polymer densities.

\begin{tabular}{|c|c|}
\hline Polymer & $\begin{array}{c}\text { Density } \\
(\mathrm{g} / \mathrm{cc})\end{array}$ \\
\hline Polyphosphazene & 1.44 (experimental) \\
\hline Filled phenolics & 1.38 to 1.84 \\
\hline Polytetrafluoroethylene & 2.14 to 2.20 \\
\hline Epoxies & 0.96 to 1.94 \\
\hline High-density polyethylene & 0.96 \\
\hline Polypropylene & 0.90 \\
\hline Polymethylmethacrylate & 1.17 to 1.20 \\
\hline Polystyrene & 1.04 to 1.05 \\
\hline Polycarbonate & 1.20 \\
\hline
\end{tabular}

\section{Dielectric Constant}

The dielectric constant is a measure of the extent to which a dielectric or insulating material polarizes when placed in an electric field of specified intensity. Though several mechanisms of polarization exist, the dielectric constant reflects principally the dislocation of negative electronic tharges relative to positive nuclear charges in the atom, as well as some distortion of atomic positions within the molecules. When the material is placed in an electric field, atomic and distortional polarizations occur almost instantaneously and thus it changes in phase with the alternating field in AC circuitry. Furthermore, the energy required to polarize the atoms and molecules is released as their polarity reverses. In effect, that energy is stored in the insulating material as a simple capacitor. In quantitative terms, therefore, the dielectric constant is defined as the capacitance of a capacitor using the test material as insulation compared to that of an identical capacitor using air as the dielectric. 
The dielectric constant is significant because it reflects the amount of energy stored in the circuit itself. Although a small added capacitance may have no ill effects, it is preferable to minimize the dielectric constant rather than compensate for it throughout the circuit. Thus, a low dielectric constant is particularly desirable for communication and electronic circuits, which rely on crisp transmission of low-intensity signals. In particular, these circuits often employ a wide range of frequencies, so the dielectric constant should remain stable throughout the range.

All of the bars showed low dielectric constants, between 1 and 5, over the entire temperature and frequency range. The dielectric constants increased with temperature as expected. For all seven bars, a peak in the 0.7 to $0.9 \mathrm{GHz}$ range increased as the temperature increased. The peak is due to the interaction of water with the electric field. The water is a byproduct resulting from additional polymer curing taking place at higher temperatures. The dielectric constants measured for the cyclomatrix bar that contained no filler are shown in Figure 3. The dielectric constant increases with increasing temperature, and the peak at $0.7 \mathrm{GHz}$ in the $200^{\circ} \mathrm{C}$ curve is very evident. This curve is typical of the data collected for all of the bars as shown in Figure 4. The unfilled, cellulose, and mineral filled cyclomatrix bars all had dielectric constants under 5 . The wood flour filled cyclomatrix bar's dielectric constant started out at less than 2 at $25^{\circ} \mathrm{C}$ and increased to more than 7 at $200^{\circ} \mathrm{C}$. The phenolic bars, in general, were very similar to the cyclomatrix bars with values for the dielectric constant varying from less than 1 to approximately 5 . The phenolic bars also showed a peak at approximately $0.7 \mathrm{GHz}$ at $200^{\circ} \mathrm{C}$. The peak in the phenolic/mineral bar was the lowest. From these data, it is concluded that the cyclomatrix materials have low dielectric constants and that the cyclomatrix materials could replace phenolics in electrical applications.



Figure 3. Dielectric constants of the unfilled cyclomatrix material. Temperatures: $25^{\circ} \mathrm{C}=\square$ $\square ; 50^{\circ} \mathrm{C}=+-+; 100^{\circ} \mathrm{C}=*-* ; 150^{\circ} \mathrm{C}=\square-\square ; 200^{\circ} \mathrm{C}=\mathrm{x}-\mathrm{x}$. 


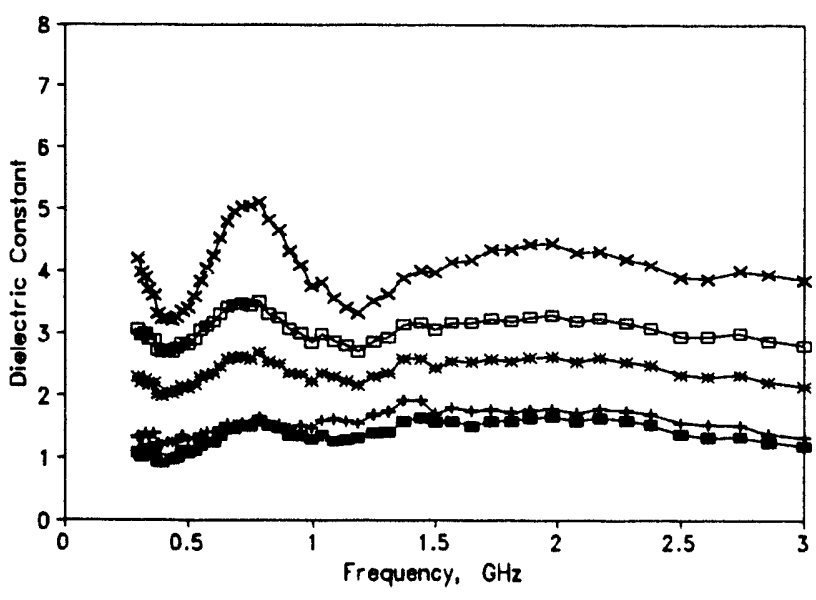

(a) Cyclomatrix - cellulose

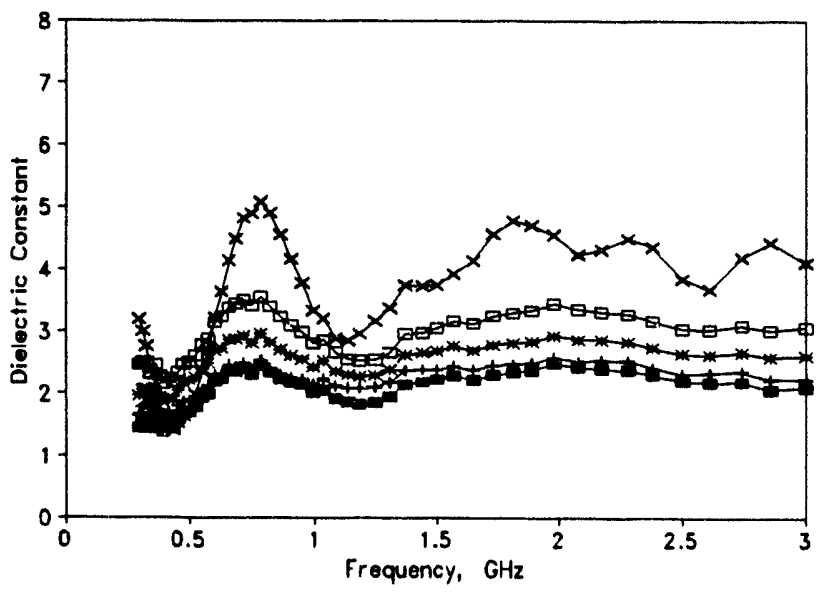

(c) Cyclomatrix - mineral

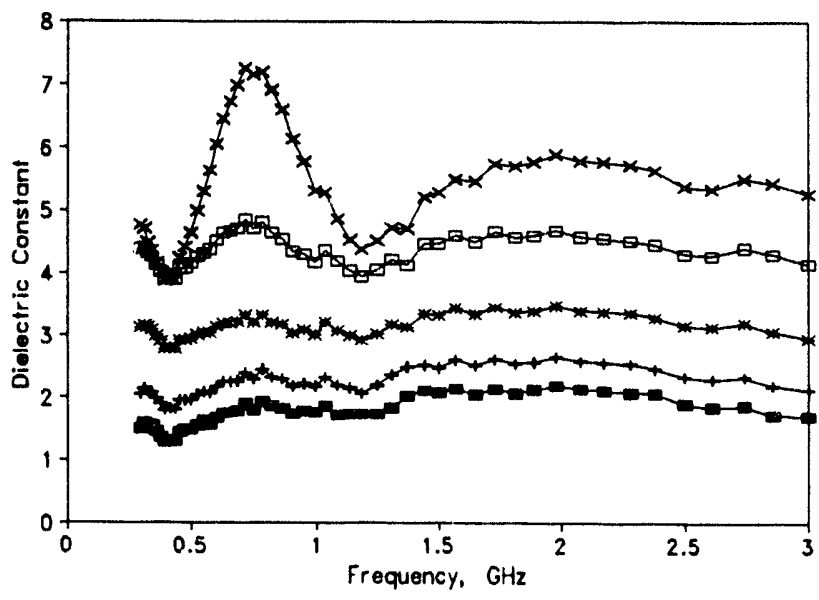

(e) Cyclomatrix - wood flour

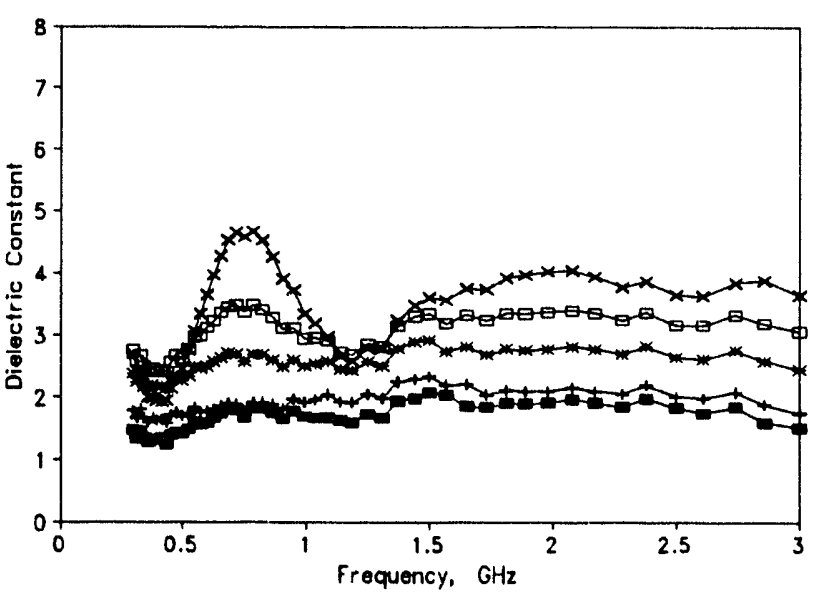

(b) Phenolic - cellulose

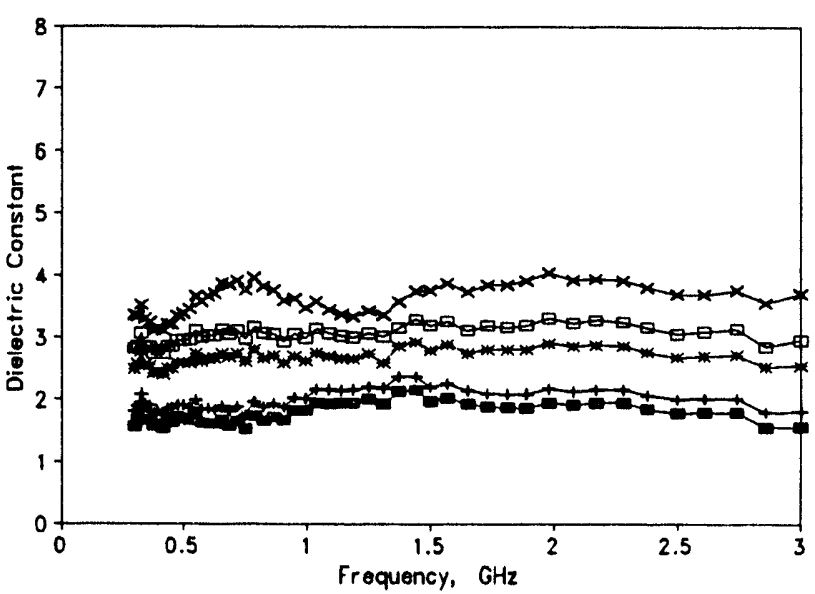

(d) Phenolic - mineral

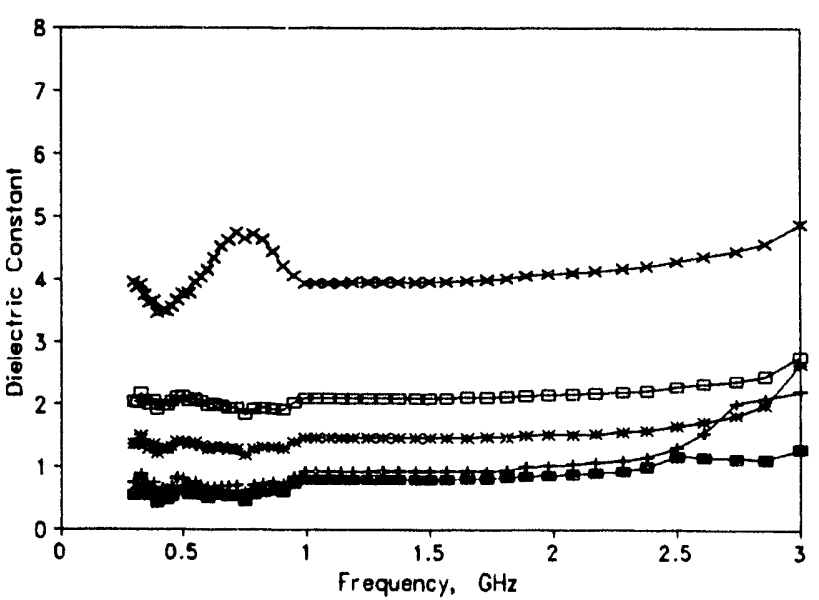

(f) Phenolic - wood flour

Figure 4. Dielectric constants of the six filled materials (as indicated). Temperatures: $25^{\circ} \mathrm{C}=\square-\square 0^{\circ} \mathrm{C}=+-+; 100^{\circ} \mathrm{C}=*-* ; 150^{\circ} \mathrm{C}=\square-\square ; 200^{\circ} \mathrm{C}=\mathrm{x}-\mathrm{x}$. 
The dielectric constants of some commercially available polymers measured at $1 \mathrm{MHz}^{2}$ are listed in Table 2. The data serve as a frame of reference and show that the values for the cyclomatrix materials are comparable to those for other polymers.

Table 2. The dielectric constants for selected polymers at $1 \mathrm{MHz}$.

\begin{tabular}{|c|c|}
\hline Polymer type & $\begin{array}{c}\text { Dielectric } \\
\text { constant range }\end{array}$ \\
\hline Cellulose acetate, molding & 3.2 to 7.0 \\
\hline Cellulose acetate, sheet & 4.0 to 5.5 \\
\hline Epoxy cast resin & 3.6 \\
\hline Methylmethacrylate & 2.7 to 3.2 \\
\hline Nylon & 3.5 \\
\hline Polyester rigid cast resin & 2.8 to 4.1 \\
\hline Polyethylene & 2.3 \\
\hline Polytetrafluoroethylene & 2.0 \\
\hline Rubber & 2.4 to 2.8 \\
\hline
\end{tabular}

\section{Elastic Moduli}

Table 3 lists the shear modulus, Young's modulus, Poisson's ratio, and bulk modulus of five unfilled cyclomatrix materials, made using slightly different processing conditions, as measured by ASTM E 949. The data show that there is excellent consistency among the samples and that the materials are very stiff. Young's modulus is a measure of the stiffness. and Figure 5 gives a comparison of the unfilled cyclomatrix materials with commercial resins. ${ }^{3}$

\section{Rockwell Hardness}

The Rockwell hardness tests were used to determine the hardness of the unfilled cyclomatrix materials. These materials proved to be very hard, having an $\mathrm{M}$ scale value of more than 120. Figure 6 compares the phosphazene materials (tested in-house) with other polymers (taken from the literature ${ }^{4}$ ). All of the other polymers were filled, thus adding to their hardness. 
Table 3. Cyclomatrix moduli derived from ultrasonic velocity measurements.

\begin{tabular}{lcccc}
\hline $\begin{array}{c}\text { Sample } \\
\text { number }\end{array}$ & $\begin{array}{c}\text { Shear } \\
\text { modulus } \\
(\mathrm{psi})\end{array}$ & $\begin{array}{c}\text { Young's } \\
\text { modulus } \\
(\mathrm{psi})\end{array}$ & $\begin{array}{c}\text { Poisson's ratio } \\
(\mathrm{psi})\end{array}$ & $\begin{array}{c}\text { Bulk modulus } \\
(\mathrm{psi})\end{array}$ \\
\hline $139-1$ & 400,040 & $1,086,240$ & 0.356 & $1,259,980$ \\
$132-1$ & 400,040 & $1,086,240$ & 0.356 & $1,258,520$ \\
$131-2$ & 400,040 & $1,086,240$ & 0.357 & $1,270,200$ \\
$137-2$ & 397,120 & $1,078,940$ & 0.356 & $1,251,220$ \\
$131-1$ & 402,960 & $1,095,000$ & 0.358 & $1,286,260$ \\
\hline
\end{tabular}

\section{Statistical Set of Experiments for Optimizing Test Bar Fabrication}

The general procedure for making a test specimen involves many steps: polymer synthesis, mixing the polymer and curing agent together, partially curing (i.e., precuring), molding, and a final heat treatment (postcuring). The process contains at least 10 parameters that influence the results. To find out the relative importance and interactions of these parameters, a statistically designed fractional factorial set of experiments was developed. The results of this set of experiments produced a recipe that generated a usable but unoptimized bar. One more set of experiments, involving intermediate values, would be required to develop a process that yields optimum mechanical values.

The statistically designed experiments used the results of samples made with each variable at its lowest and highest values. The 10 identified process variables were: particle size of the precured polymer, curing agent concentration [hexamethylenetetramine (HMTA)], size of the precuring batch, precuring temperature, precuring time, molding pressure, molding temperature, molding time, postcuring temperature, and postcuring time. The experimental design requires that 12 samples be made and that at least three bars be obtained for each condition, for a total of 36 bars. Selection of high and low values of the parameters was based on experience. The powder produced by the precuring process was loaded into a picture frame mold and heated and pressed into the final rectangular shape. One prime consideration was that the viscosities of the polymers (at the time of molding) be sufficiently low to allow it to flow into the desired bar shape, but not so low as to run out of the mold. Viscosity is controlled by precuring temperature and time. High and low temperatures and precuring times were carefully selected in an attempt to produce useful bars (for flexural strength measurements) in each experiment. Even with careful control, several experiments did not produce usable bars. 


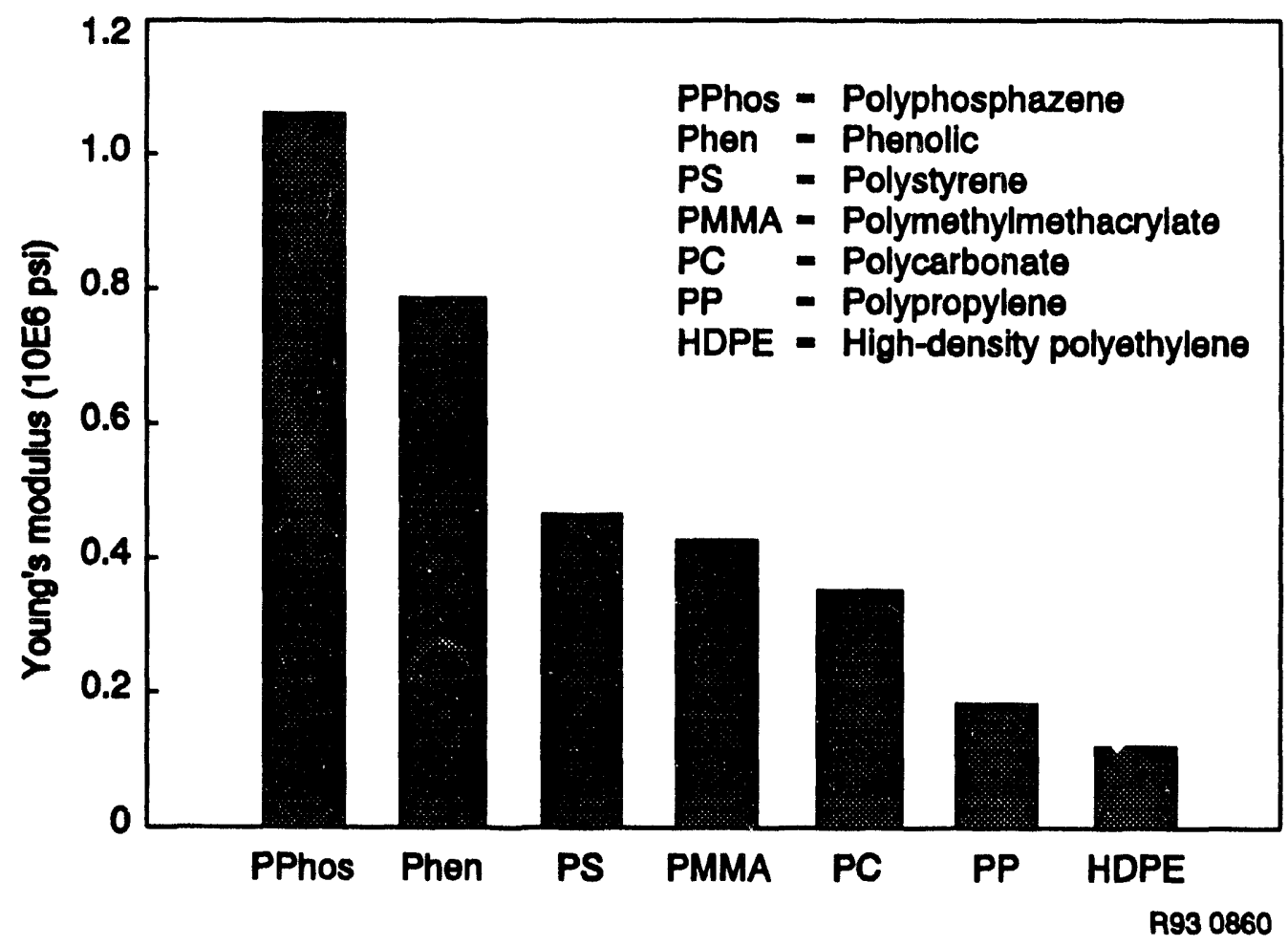

Figure 5. Young's modulus comparison.

Polyphosphazene

Phenolics, filled

Polyethylene terephthalate, glass

Polyamides, glass

Polyphenylene oxide, glass

Polycarbonate, glass

Acrylonitrile-butadiene-

styrene, glass 
Bars were produced with a wide range of appearance and performance results. Some bars looked good and performed well, others looked good but broke or cracked when removed from the mold (preventing mechanical testing), and some were full of bubbles and cracks.

The experimental design produced what are termed B-coefficients. The B-coefficients were used to rank the importance of the variables and to indicate whether the high value or the low value of the variable was most beneficial. Table 4 shows the ranked B-coefficients for the 10 parameters evaluated in this experimental design; the higher the absolute value of the B-coefficient, the higher the effect of the parameter on the response. This ranking allows the experimenter to select the most important parameters to be used in process optimization. The sign of the B-coefficient is not involved in the ranking; it only signifies whether the high (+) or low (-) value of that particular parameter has the greatest effect on the response. Optimum conditions for bar production should be approached by selecting the high or low value for each variable based upon a + or - value of the parameter in Table 4, respectively. These tests showed that the five most influencial parameters are related to polymer viscosity.

Table 4. B-coefficient ranking of the design variables.

\begin{tabular}{lllll}
\hline Rank & \multicolumn{1}{c}{ Variable } & B-coefficient & Effect & Variable value \\
\hline 1 & Precure temp & 1296 & + & $115^{\circ} \mathrm{C}$ \\
2 & Mold temp & 971 & + & $177^{\circ} \mathrm{C}$ \\
3 & Batch size & -863 & - & $7 \mathrm{~g}$ \\
4 & Mold time & 742 & + & $15 \mathrm{~min}$ \\
5 & Precure time & 457 & + & $75 \mathrm{~min}$ \\
6 & Mold pressure & -243 & - & $2,000 \mathrm{psi}$ \\
7 & Ball mill time & -121 & - & $2 \mathrm{~min}$ \\
8 & Postcure temp & -55 & - & $100^{\circ} \mathrm{C}$ \\
9 & Postcure time & 46 & + & $80 \mathrm{~min}$ \\
10 & HMTA concentration & 22 & + & $20 \mathrm{wt} \%$ based upon polymer \\
\hline
\end{tabular}




\section{Coefficients of Linear Thermal Expansion}

The linear thermal expansion coefficients were determined for the unfilled and the three filled composites. The coefficients are similar to those of other polymers. Since many of the other polymers are used as matrices for commercial composites, it implies that the expansion coefficients of the cyclomatrix polyphosphazene materials will also be suitable. Table 5 lists the expansion coefficients for several polymer systems, including the polyphosphazene bars. ${ }^{4}$

Table 5. Coefficients of linear thermal expansion.

\begin{tabular}{ll}
\multicolumn{1}{c}{ Polymer system } & \multicolumn{1}{c}{$\begin{array}{c}\text { Thermal } \\
\text { expansion } \\
\text { coefficient } \\
\left(\times 10^{-6} \mathrm{~cm} / \mathrm{cm}^{\circ} \mathrm{C}\right)\end{array}$} \\
\hline Unfilled polyphosphazene & 71 \\
Polyphosphazene, woodflour & 41 \\
Polyphosphazene, cellulose & 13 to 21 \\
Polyphosphazene, mineral & 42 \\
Phenolic, woodflour & 30 to 45 \\
Polytetrafluoroethylene (teflon) & 77 to 100 \\
Epoxy, mineral & 20 to 60 \\
High-density polyethylene, unfilled & 59 to 110
\end{tabular}

\section{Chopped Glass Filled Bars}

The results for the chopped glass are presented as a separate section, because the research was conducted at a later date and because some changes were made in the fixtures, which were used to measure flexural strengths, just before the glass filled samples were measured.

Ordinarily, chopped glass to be used in composites comes in small bundles held together by a sizing or finish to aid in handling. These small bundles are combined with the resin in a heated, high-shear mixing section of an extruder prior to molding. The heating and mixing break up the bundles and disperse the fibers in the resin. Many fibers are broken, but are still long enough to give the composite good properties. It is a difficult process to make a single bar without the aid of an extruder. Chemical attempts to strip the sizing were unsuccessful. When the sizing was 
burned off, the fibers would not disperse. Instead, they would 'cotton ball'. After several variations were performed with sized $1 / 4$ and $1 / 8$ in. long fibers, we found that smaller unsized $1 / 16$ in. fibers could be handled like a powdery filler, and so they were selected for these experiments.

The first bars made contained 60 wt\% fibers and had flexural strengths of less than 10,000 psi. However, the addition of a small amount of a silane ( $\sim 0.1 \%$ of 3 -glycidyloxytrimethoxysilane) coupling agent caused an increase in the flexural strengths, in some samples close to 13,000 psi. The silane is formulated so that one end of the molecule forms a strong bond to the glass fibers and the other end mixes into or chemically attaches to the polymer. Thus, the coupling agent was added in all of the bars reported herein. It is surprising that the glass fiber filled bars have lower flexural strengths than bars with some of the other fillers. Factors that might affect this result are the aspect ratios of the fillers, adhesion to the fillers, and stiffness of the fillers.

\section{Flexural Strengths and Relative Modulus}

The flexural strengths of both the cyclomatrix and phenolic composites were determined at room temperature. Figure 7 gives the average strength values (three bars tested) for an unfilled cyclomatrix bar, three filled cyclomatrix bars (60\% filler by weight), and three filled phenolic bars (amount of filler unknown). The filler did improve the strength of the cellulose and wood flour filled cyclomatrix bars. However, the mineral filled cyclomatrix strengths values were reduced. All three of the phenolic bar types had similar properties. Two of the filled cyclomatrix systems (cellulose and woodflour) had superior properties over the corresponding phenolic. The mineral filled cyclomatrix was lower than its phenolic counterpart. The fibrous cellulose filler gave the cyclomatrix the best properties of these three systems. Scanning electron microscope (SEM) photos showed that there was a significant amount of glass fibers in the phenolic mineral filled bars. This could easily explain why the phenolic mineral filled bars were better than the cyclomatrix bars. Generally, it was observed that the flexural strengths of the cyclomatrix bars were higher than the phenolics.

When the flexural strengths are measured, a plot of force versus displacement was produced. The slope of the plot is related to the stiffness of the material. If one uses the slope of the unfilled cyclomatrix bar to normalize all of the other slopes, a quantity called the relative modulus results, giving a measure of the stiffness of the bar being tested relative to the unfilled cyclomatrix bar. The results of that calculation for each of the six filled bars are shown in Figure 8. These results clearly show that the cyclomatrix systems are stiffer than their corresponding phenolic composites.

\section{Chemical Resistance}

Figure 9 gives the results of the flexural strength tests after the bars had soaked for 3 weeks in the four organic solvents. The results were a little surprising, since most bars showed higher flexural strength values after soaking than the controls that had not been soaked. This was true for all of the phenolics in all the solvents. The cellulose and woodflour filled cyclomatrix materials were slightly improved after soaking, whereas both the unfilled and mineral filled lost substantial strength. 


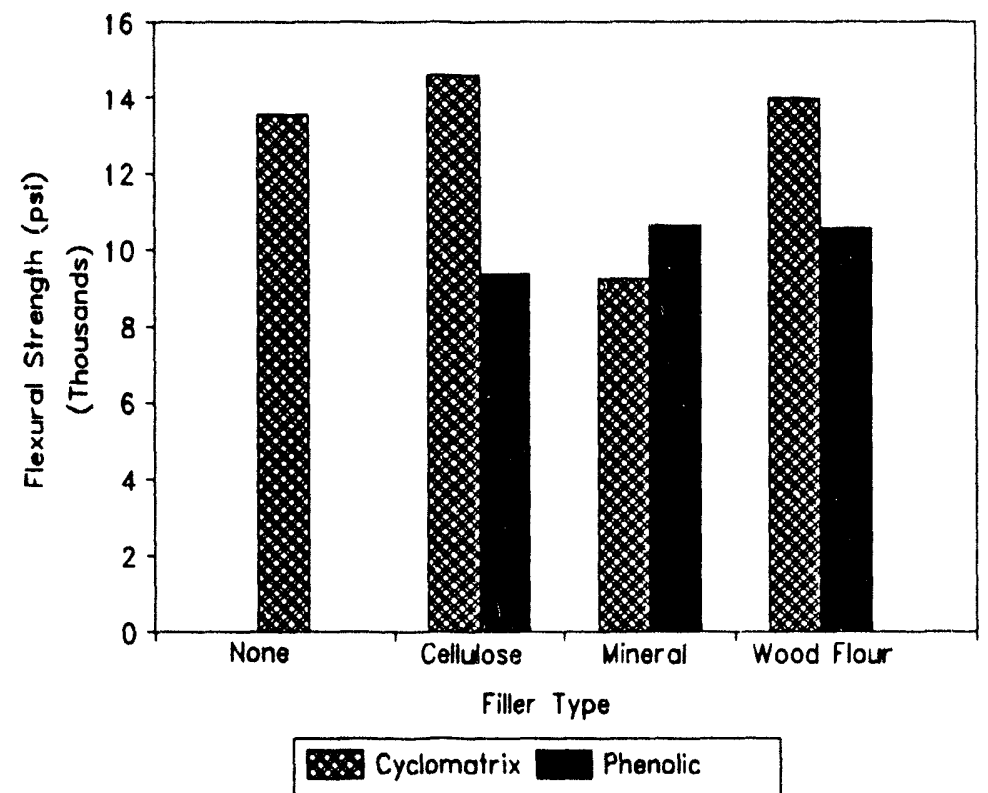

Figure 7. Flexural strengths of cyclomatrix and phenolic bars.

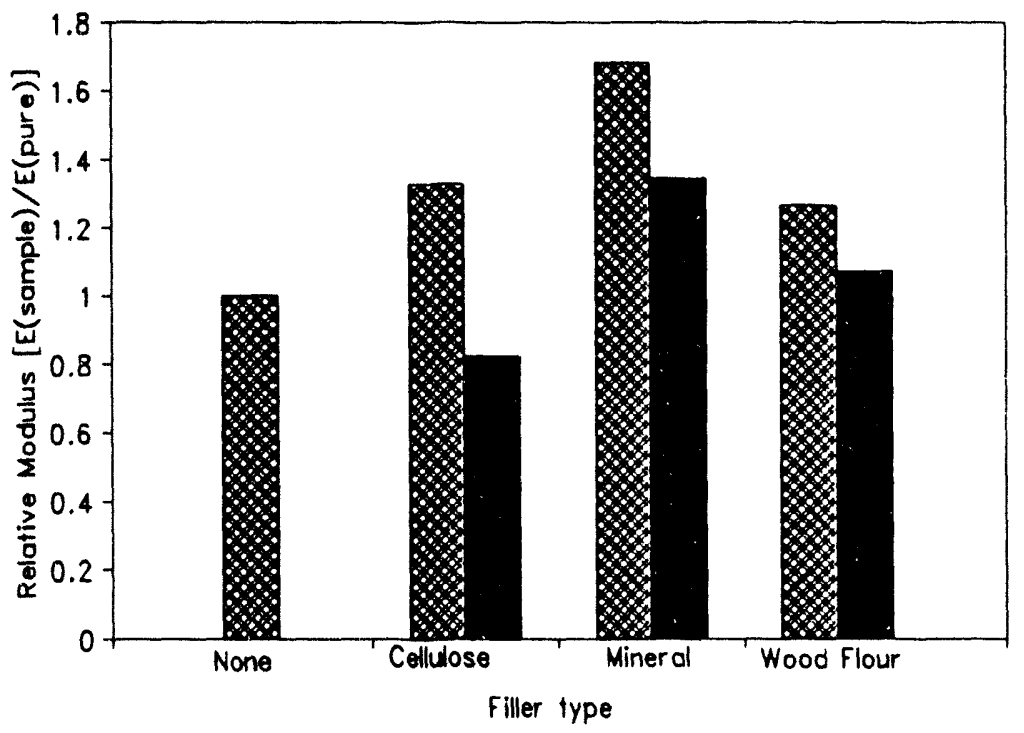

\$8 Cyclomatrix Phenolic

Figure 8. Relative modulus of cyclomatrix and phenolic bars. 


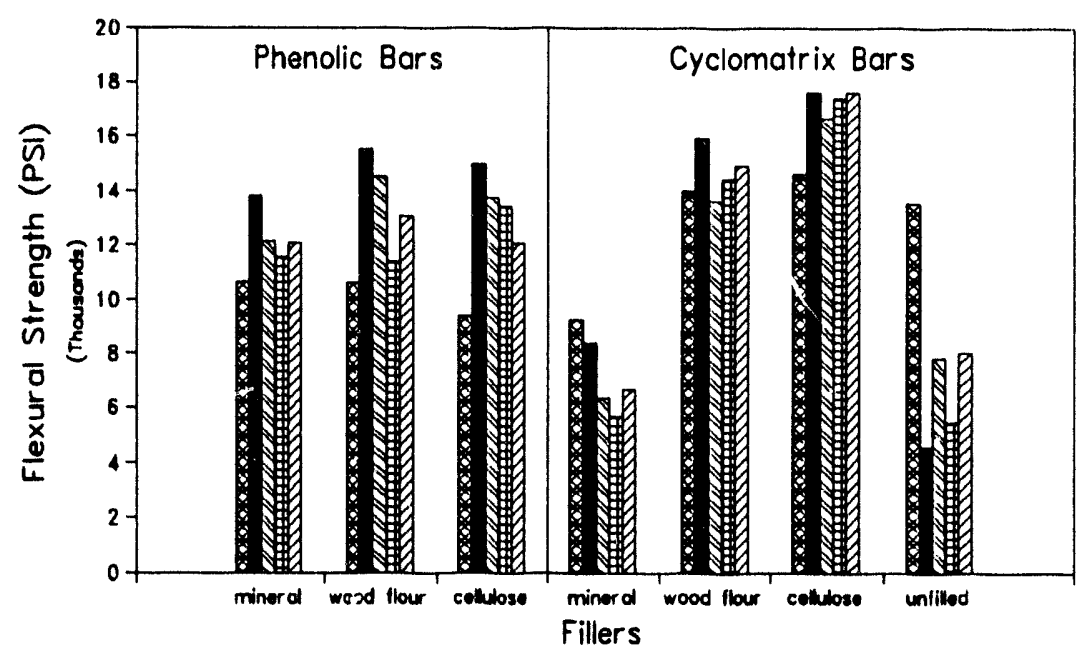

$\begin{array}{ll}\text { Ensooked } & \text { Ethanol } \\ \text { Acetone }\end{array}$

Figure 9. Flexural strengths after immersion in organic solvents for 3 weeks at room temperature.

The base ( $0.1 \mathrm{M}$ sodium hydroxide) and the acid (1 M sulfuric acid) soaked flexural strength test results are shown in Figure 10. All three phenolic composites showed some improvement after being exposed to the base, and all three lost some strength after exposure to the acid. All of the cyclomatrix materials were adversely affected by both the acid and the base.

The chemical resistance was also measured by monitoring the changes in weight and appearance of pieces of the bars immersed at room temperature in six different liquids for a year.

\section{Organic Liquids (Ethanol, Toluene, Acetone, and Methylene Chloride)}

After a year of immersion in these solvents, all eight bars (five phosphazene and three phenolic) showed less than $1.5 \%$ change in weight and no change in appearance.

\section{Aqueous Acid and Base (1 $\mathrm{M} \mathrm{H}_{2} \mathrm{SO}_{4}$ and $1 \mathrm{M} \mathrm{NaOH}$ )}

The unfilled cyclomatrix bars gained less than $5 \%$ in weight in the acid, but lost over $20 \%$ in the first 5 weeks of exposure to the base. The cyclomatrix/cellulose bars gained $\mathbf{3 0}$ to $50 \%$ in weight in the first 5 to 7 weeks in both fluids. The cyclomatrix/mineral gained about $10 \%$ in the acid in the first 7 weeks and has remained constant thereafter. It deteriorated completely in 5 weeks in the base. The cyclomatrix/woodflour bar also gained about $10 \%$ in the acid. After 7 weeks, though it did not deteriorate completely, it severely degraded. The cyclomatrix/glass has shown no degradation in the acid at all, but after 3 to 7 weeks exposure to the base it lost nearly $20 \mathrm{wt} \%$ and continues to degrade. 


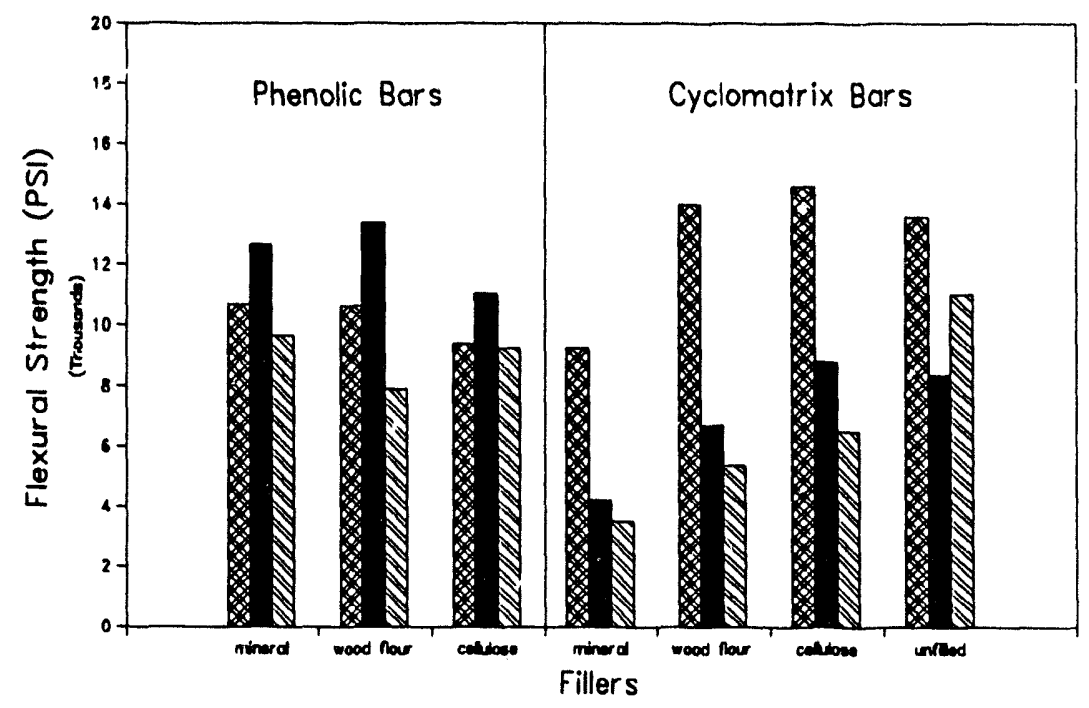

Unsoaked Sodium Hydroxide Sulfuric Acid

Figure 10. Flexural strengthis atter immersion in acid and base for 3 weeks at room temperature.

The glass filled cyclomatrix bars showed better flexural strengths after exposure to the acid and base than the other cyclomatrix formulations (Figure 11).

After exposure for 1 year, all three of the phenolic composites gained between 10 and $35 \mathrm{wt} \%$ and degraded severely in both the acid and base.

\section{Oxidation Tests}

Another important characteristic studied was how well the materials survived heating in air. Pieces of each bar type were placed in an oven at selected temperatures for various times. The appearance and weight loss were used to measure the thermal/oxidative stability. Table 6 lists the results. The data show that the inorganic filled and the unfilled bars performed best. The chopped glass cyclomatrix bars showed the lowest weight loss. Another observation is that most of the weight was lost in the first hour.

A longer term, 8-week trial was run at $200^{\circ} \mathrm{C}$ (Table 7). This temperature was arbitrarily chosen because all of the bars lost less than $5.5 \%$ of their weight after 2 hours of exposure at this temperature.

The mineral and glass filled polyphosphazenes outperformed the phenolics in this oxidation test. Th unfilled phosphazene bar performed better than the phenolics, too. The results show that the inorganic fillers are suited for higher temperatures, whereas the organic fillers apparently failed by decomposing. The fiberglass and mineral filled cyclomatrix filled materials lost less than $2 \%$ of their weight during the entire period. 


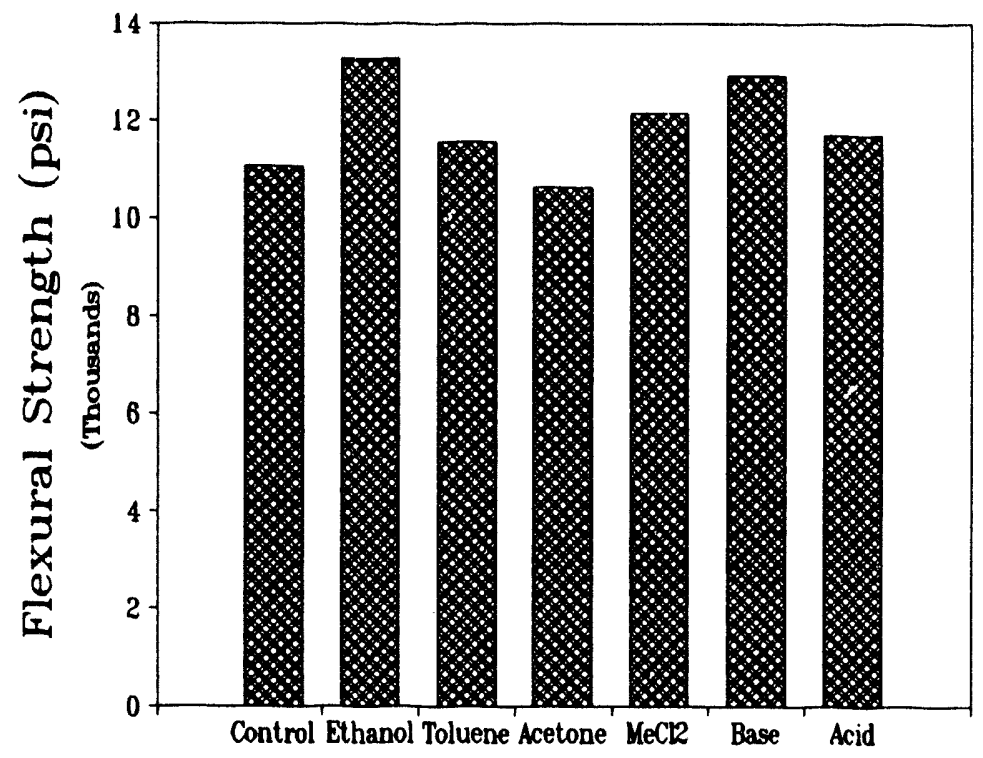

Figure 11. Flexural strengths of chopped glass filled polyphosphazene composites after 3 weeks of immersion in the indicated chemicals at room temperatures. (Acid and base concentrations were 1M.)

All of the bars' appearances changed over the 8 weeks of exposure. Most of the bars turned grey-black. However, the cellulose and woodflour filled cyclomatrix bars blistered after 4 weeks of exposure.

\section{Stress Corrosion}

The application of a liquid chemical to a material under stress often hastens degradation. Thus, in metals and in certain types of plastics, a stress corrosion experiment can be important to decide if a material will be suitable for uses in which both chemicals and mechanical stresses are present simultaneously. There are not any ASTM or SAE stress tests for hard, rigid, plastic materials. So, an SAE test for a flexible material was modified to give a workable stress corrosion test [SAE J2016 (June 1989, "Chemical Stress Resistance of Polymers")] calls for the sample to be flexed and then subjected to the chemicals of interest for three 10-minute intervals. After each interval, the surface is examined under a microscope $(\geq 20 \times)$ to see if any stress cracking or other surface features had developed. A stressing jig was built that duplicated the four-point flexural strength test.

To perform the test, a sample bar was loaded in the testing jig for a total exposure time of 30 minutes and flexed to approximately 10 to $25 \%$ of its breaking point. The surface of the bar in tension was kept wet with the chemicals by applying drops or by painting it with a cotton swab. Then, according to the test, the surface was examined for cracks or other changes. The unfilled and fiberglass filled polyphosphazene bars were used in this test. The same six chemicals used in 
Table 6. Total weight loss (wt\%) after heating for 1 hour and 2 hours at the indicated temperatures.

\begin{tabular}{|c|c|c|c|c|c|c|}
\hline Sample & $\begin{array}{l}300^{\circ} \mathrm{C} \\
\text { for } 1 \mathrm{hr}\end{array}$ & $\begin{array}{c}300^{\circ} \mathrm{C} \\
\text { for } 2 \mathrm{hr}\end{array}$ & $\begin{array}{c}250^{\circ} \mathrm{C} \\
\text { for } 1 \mathrm{hr}\end{array}$ & $\begin{array}{l}250^{\circ} \mathrm{C} \\
\text { for } 2 \mathrm{hr}\end{array}$ & $\begin{array}{l}200^{\circ} \mathrm{C} \\
\text { for } 1 \mathrm{hr}\end{array}$ & $\begin{array}{l}200^{\circ} \mathrm{C} \\
\text { for } 2 \mathrm{hr}\end{array}$ \\
\hline PM & 10.1 & 10.7 & 4.8 & 5.8 & 1.7 & 2.4 \\
\hline PW & 17.9 & 19.4 & 8.1 & 9.4 & 2.8 & 3.8 \\
\hline PC & 18.5 & 19.8 & 8.1 & 9.8 & 2.5 & 3.4 \\
\hline $\mathrm{CM}$ & 3.3 & 3.3 & 1.7 & 2.8 & 0.6 & 0.7 \\
\hline $\mathrm{CW}$ & 25.6 & 25.9 & 15.7 & 17.8 & 4.8 & 5.5 \\
\hline $\mathrm{CC}$ & 30.7 & 32.7 & 15.7 & 22.0 & 3.5 & 4.0 \\
\hline $\mathrm{CU}$ & 6.0 & 6.1 & 3.9 & 4.3 & 2.2 & 2.6 \\
\hline CG & 2.3 & 2.3 & 1.7 & 1.8 & 0.3 & 0.5 \\
\hline \multicolumn{7}{|c|}{ Sample Designation Key: } \\
\hline \multicolumn{3}{|c|}{$\begin{array}{l}\text { First letter: } \\
P=\text { phenolic } \\
C=\text { cyclomatrix polyphosphazene }\end{array}$} & \multicolumn{2}{|c|}{$\begin{array}{l}\text { Second letter: } \\
M=\text { mineral } \\
W=\text { woodflour } \\
C=\text { cellulose } \\
U=\text { unfilled } \\
G=\text { chopped glass }\end{array}$} & & \\
\hline
\end{tabular}

Table 7. Weight loss after 8 weeks of heating at $200^{\circ} \mathrm{C}$ in air.

\begin{tabular}{lc}
\multicolumn{1}{c}{ Composite type } & $\begin{array}{c}\text { Weight loss } \\
(\%)\end{array}$ \\
\hline Cyclomatrix polyphosphazene, unfilled & 5 \\
Cyclomatrix polyphosphazene, chopped glass filled & 2 \\
Cyclomatrix polyphosphazene, mineral filled & 2 \\
Cyclomatrix polyphosphazene, cellulose filled & 31 \\
Cyclomatrix polyphosphazene, woodflour filled & 18 \\
Phenolic, mineral filled & 7 \\
Phenolic, cellulose filled & 20 \\
Phenolic, woodflour filled & 11 \\
\hline
\end{tabular}


the chemical resistance tests were used in the stress corrosion study (acetone, ethanol, methylene chloride, toluene, $1 \mathrm{M} \mathrm{H}_{2} \mathrm{SO}_{4}$, and $1 \mathrm{M} \mathrm{NaOH}$ ). The same bar was used for all of the chemicals tested. For both bar types, no changes at all were noted. Thus, short-term exposure under the loading conditions selected is not harmful.

\section{Elevated Temperature Flexural Strengths}

Based upon the oxidation study, glass, mineral, unfilled polyphosphazene, and mineral filled phenolic bars were selected for elevated temperature flexural strength testing. Bars were tested at $100,200,300,350$, and, in some cases, $400^{\circ} \mathrm{C}$. The glass filled samples performed the best and were tested at all temperatures. The bars were very dark in color, but did not blister. The reason for the increase in strength at the highest temperatures for two of the polyphosphazene materials is unknown. Figure 12 gives the results.

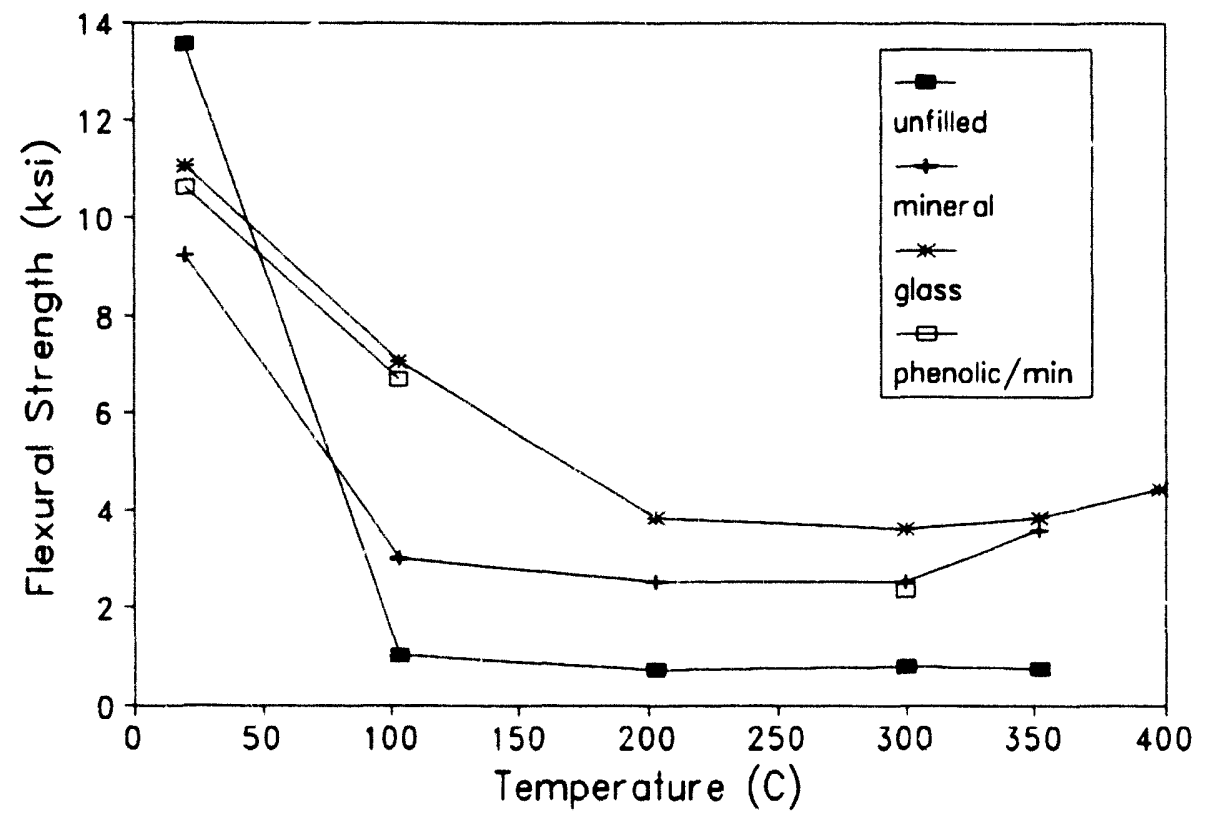

Figure 12. Elevated temperature flex strengths. 


\section{CONCLUSIONS}

Inorganic polymers, based on alternating nitrogen and phosphorus skeletons, are of interest for their potential use as the matrix materials in composites. Much of the interest in this field stems from the synthetic versatility of the phosphazene polymers. The preparative chemistry of the polyphosphazene is the most highly developed of all the inorganic polymer systems. More than $\mathbf{3 0 0}$ polymers have been synthesized. In addition to the chemical variety, there are three known backbone configurations. All of these parameters make it possible to design and tailor-make polymers to fit a specific application.

A polyphosphazene with a cyclomatrix backbone was selected for this work because extensive crosslinking makes the materials hard and rigid, with good chemical resistance and thermal stability properties. It was determined that the material has excellent chemical resistance to many types of organic solvents and was harder than most commercially available resins. Its mechanical and dielectric properties were similar to phenol-formaldehyde phenolics.

Time did not permit complete process optimization. There are at least 10 parameters that influence the quality of sample bar produced. A statistically designed set of experiments was extremely useful in determining which parameters had the greatest influence. The tests showed that the most critical aspect during processing was the viscosity of the resin. The viscosity had to be controlled so that when heated and pressed the polymer flowed to conform to the shape of the mold, but did not flow from the mold during pressing.

The polyphosphazene formulations tested showed no significant changes in weight or appearance after immersion at room temperature for a year in acetone, ethanol, toluene, and methylene chloride. However, the flexural strengths were affected. In some cases, strengths were higher; in other cases, they were lower. The reason for this difference is not understood.

Neither the phosphazenes nor the phenolics were resistant to attack from aqueous acid or base. After 3 to 7 weeks of exposure at room temperature to $1 \mathrm{M}$ sodium hydroxide, all of the materials had severely deteriorated, indicated by their change in weight and appearance.

The flexural strength data for the phenolics do not agree with the weight change information, since the values increased after exposure to the base for 3 weeks. The phenolics apparently were tested just before they deteriorated.

Of the four fillers used in making the composites, the chopped fiberglass gave the best results. It was determined that a small amount of a silane coupling agent improved the mechanical properties considerably. Also, the chopped glass provided thermal stability to the composite allowing use of the material in high-temperature applications. One unexpected result was that the flexural strengths of the glass filled bars were not significantly better than those of the other fillers with a smaller aspect ratio. However, the properties of the glass filled polyphosphazenes would be expected to be much improved when larger batchs of the materials are formulated using extruders equipped with proper heaters and mixing screws.

The polyphosphazene composites containing glass, cellulose, or woodflour show potential for application requiring high thermal and organic chemical resistance. Applications might include 
chemical pump housings and blades, doctor blades, pipes or pipe liners, and chemical processing tanks. Under-the-hood automotive applications would include such items as intake manifolds, distributor caps, fuel line components, and valve covers.

It is important to remember that this program only looked at the properties of one of the hundreds of possible formulations of polyphosphazenes. This is the first time that polyphosphazene composite properties have been tabulated. The fact that the properties were as good as, and, in several instances, better than the properties of commercially available materials is highly encouraging, since phenolics have been studied and improved for more than $\mathbf{8 0}$ years. Considerable work remains to make the materials commercially viable, but the initial set of properties obtained in this scoping study indicates that the chances for success are excellent. 


\section{REFERENCES}

1. Modern Plastics Encyclopedia '92, Vol. 68, No. 11, McGraw Hill, Section 7.

2. CRC Handbook of Chemistry and Physics, Chemical Rubber Co., 1969, p. E-66.

3. Engineering Plastics, (ASM International, Metals Park, OH, 1988), Vol. 2, pp. 242-245.

4. Modern Plastics Encyclopedia '93, (McGraw-Hill, Inc., NY, 1992), pp. 240-241. 

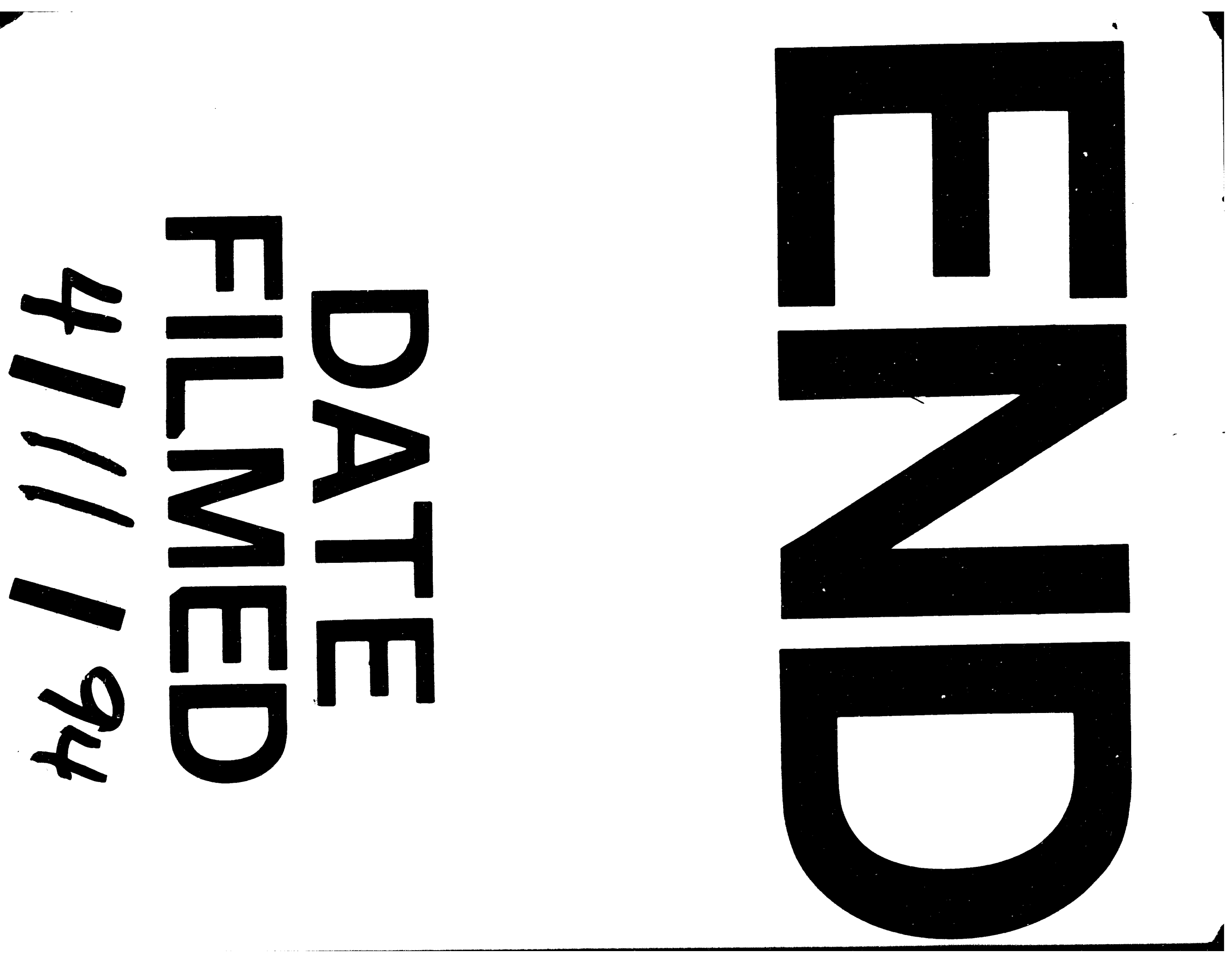
